\title{
KAJIAN TEKNIS AKTIFITAS DEWATERING DI AREA PENAMBANGAN IUP PT DUTA ALAM SUMATERA PERIODE BULAN MARET TAHUN 2020
}

\section{TECHNICAL STUDY OF DEWATERING ACTIVITIES IN THE MINING AREA OF PT DUTA ALAM SUMATRA IUP FOR THE PERIOD OF MARCH 2020}

\author{
Rusdiana $^{1)}$, Lina Rianti ${ }^{2)}$, M. Ikbal Aziz ${ }^{3)}$ \\ ${ }^{1,2,3)}$ Program Studi Teknik Pertambangan Batubara Politeknik Akamigas Palembang, 30257, Indonesia \\ Corresponding Author E-mail: rusdianad18@gmail.com dan linarianti@pap.ac.id
}

\begin{abstract}
In an open mining system the water that enters the mining site can disrupt mining activities and reduce production plans, so water management is called a mine drainage system. This research analyzes pump outlet discharge, volume of incoming and outgoing water and sump ability. The method used to calculate runoff discharge using the rational method and to discharge the Turc-Langbein-Wund formula. Before overflowing the water in the sump, it will be moved out of the mine with a pumping and piping system to the settling pond in order to obtain a pump outlet discharge of $1,182 \mathrm{l} / \mathrm{s}$. In the investigation area has a catchment area of $287.200 \mathrm{~m}^{2}$ and sump elevation of $62.5 \mathrm{~m}$, maximum rainfall is obtained $65.23 \mathrm{~mm} /$ day, rain hour is 1.22 hours and the volume of incoming water is $5,115.08 \mathrm{~m}^{3}$ / hour. comes from runoff water, evapotranspiration water and ground water while the volume of water that comes out is 709,200 $\mathrm{m}^{3}$ / hour. The location of the sump is located to the east of the Pit with the number of pumps used, namely 6 pump units ( 5 pump units in Pit 2 sumps and 1 pump in Pit 1 sumps). The pipe used is HDPE with a diameter of $0.25 \mathrm{~m}$. The number of pipes used in the sump is 20 sticks. From observations obtained that the existing sump is able to accommodate the incoming water with a sump ability percentage of $57 \%$. To get maximum results need pump maintenance, check the actual discharge at the pump outlet and pay attention to the slope of the mine opening floor.

Keywords: Mine Drainage System, Sump, Discharge, Water and Settling Pond.
\end{abstract}

Abstrak: Pada sistem tambang terbuka air yang masuk ke lokasi penambangan dapat mengganggu aktifitas penambangan serta menurunkan rencana produksi maka dibutuhkan penanggulangan air yang dinamakan sistem penyaliran tambang. Penelitian ini menganalisis debit outlet pompa, volume air yang masuk serta keluar dan kemampuan sump. Adapun metode yang digunakan untuk menghitung debit limpasan dengan menggunakan metode rasional dan untuk debit evapotranspirasi rumus Turc-Langbein-Wund. Sebelum meluap air yang ada di sump maka akan dipindahkan keluar tambang dengan sistem pemompaan dan pemipaan menuju settling pond sehingga didapat debit outlet pompa sebesar $1.182 \mathrm{l} / \mathrm{s}$. Pada daerah penyelidikan mempunyai luas catchment area $287.200 \mathrm{~m}^{2}$ dan elevasi sump 62,5 m, curah hujan maksimum diperoleh 65,23 mm/hari, jam hujan sebesar 1,22 jam dan volume air yang masuk sebanyak 5.115,08 $\mathrm{m}^{3} / \mathrm{jam}$ yang berasal dari air limpasan, air evapotranspirasi dan air tanah sedangkan volume air yang keluar sebesar $709.200 \mathrm{~m}^{3} / \mathrm{jam}$. Letak sump berada pada sebelah timur Pit dengan jumlah pompa yang digunakan, yaitu 6 unit pompa (5 unit pompa di sump Pit 2 dan 1 pompa di sump Pit 1). Pipa yang digunakan yaitu HDPE dengan diameter 0,25 m. Jumlah pipa yang digunakan pada sump, yaitu 20 batang. Dari hasil pengamatan diperoleh sump yang ada mampu menampung air yang masuk dengan persentase kemampuan sump, yaitu $57 \%$. Untuk mendapatkan hasil yang maksimal perlu perawatan pompa, mengecek debit aktual pada outlet pompa serta memperhatikan kemiringan lantai bukaan tambang.

Kata Kunci : Sistem Penyaliran Tambang, Sump, Debit, Air dan Settling Pond.

\section{PENDAHULUAN}

\subsection{Latar Belakang}

Industri pertambangan batubara merupakan salah satu penyumbang bagi ketersediaan energi pada saat ini, baik sebagai pembangkit tenaga listrik, industri pembuatan semen, peleburan bijih besi dan baja dan masih banyak lagi. Dapat dilihat dari permintaan batubara dari pasar domestik maupun mancanegara yang meningkat tiap tahunnya.
Hal ini berdampak bagi sektor industri di Indonesia yang mengakibatkan banyaknya berdiri perusahaan tambang baru tepatnya di daerah Sumatera dan Kalimantan. Perusahaan tersebut berusaha meningkatkan produksi batubaranya untuk bersaing memenuhi permintaan pasar batubara dunia (Sibarani, Mukiat dan Abro, 2016: 2).

PT Duta Alam Sumatera merupakan salah satu perusahaan swasta dalam negeri 
yang melakukan usaha dibidang pertambangan batubara yang berlokasi di Desa Tanjung Baru, Kecamatan Merapi Barat, Kabupaten Lahat, Provinsi Sumatera Selatan dan memiliki IUP produksi dengan lahan konsesi sebesar 357 hektar. Sistem penambangan yang diterapkan oleh PT Duta Alam Sumatera adalah sistem penambangan tambang terbuka dan metode yang digunakan konvensional, dengan penambangan menggunakan alat gali muat excavator backhoe dan alat angkut, yaitu dump truck.

Metode tambang terbuka (open pit) akan menyebabkan terbentuknya cekungan yang luas sehingga sangat potensial untuk menjadi daerah tampungan air, baik yang berasal dari air limpasan permukaan maupun air tanah. Pada saat kondisi cuaca ekstrim berupa adanya curah hujan yang tinggi maka air yang berasal dari limpasan permukaan dapat menggenangi lantai dasar dan menyebabkan berlumpurnya front penambangan sehingga membawa dampak kerugian bagi perusahaan. Disamping itu, material yang dibawa oleh air limpasan jika tidak ditangani dengan baik akan berdampak terhadap kerusakan ekosistem sekitar.

Pengamatan di lapangan terlihat adanya daerah tangkapan hujan yang luas. Permasalahan tersebut akan menghambat aktifitas penambangan yang mengakibatkan tidak tercapainya target produksi. Diperlukan suatu bentuk upaya yang optimal untuk penanganan air yang masuk ke pit melalui suatu bentuk kajian teknis aktifitas dewatering dengan menganalisis semua aspek yang berpengaruh terhadap penanganan air yang masuk ke pit. Melalui upaya penanganan air yang masuk ke pit, maka diharapkan permasalahan yang timbul akibat tidak terkontrolnya air yang masuk ke pit dapat dihindari dan diminimalisir, sehingga aktifitas penambangan tetap dapat dilakukan walaupun dalam cuaca yang ekstrim (Yusran, Djamaluddin dan Budiman, 2015:1-2).

\subsection{Batasan Masalah}

Batasan masalah dalam penelitian ini, yaitu Kajian teknis dewatering pada periode bulan maret tahun 2020., Penelitian tidak mempertimbangkan analisis biaya hanya berupa kajian teknis meliputi performa pompa dan dimensi Sump., dan Penelitian dilaksanakan di Area KPL 3.

\subsection{Tujuan Penelitian}

Tujuan dari penelitian ini adalah :

1. Mengetahui debit outlet pompa yang akan masuk di area KPL 3.

2. Mengetahui total volume air masuk dan total volume air yang keluar dari area penambangan.

3. Mengetahui kemampuan dimensi Sump di area Pit 2.

\subsection{Manfaat Penelitian}

Manfaat dari penelitian ini adalah

1. Dapat digunakan untuk menggambarkan aktifitas dewatering di area penambangan PT Duta Alam Sumatera.

2. Dapat digunakan untuk menggambarkan performa pompa yang bekerja di area $P$ it 2 .

3. Dapat memberikan masukan untuk perusahaan terhadap kemampuan dimensi sump di area Pit 2.

\section{TEORI DASAR}

\subsection{Sistem Penyaliran Tambang}

Pengertian dari sistem penyaliran tambang adalah suatu usaha yang diterapkan pada daerah penambangan untuk mencegah, mengeringkan, atau mengeluarkan air yang masuk ke daerah penambangan. Upaya ini dimaksudkan untuk mencegah terganggunya aktifitas penambangan akibat adanya air dalam jumlah yang berlebihan, terutama pada musim hujan dan juga untuk memperlambat kerusakan pada alat, sehingga tahan lama (Suwandhi, 2004).

Sumber air yang masuk ke lokasi penambangan dapat berasal dari air permukaan tanah maupun air di bawah tanah. Air permukaan tanah merupakan air yang terdapat dan mengalir di permukaan tanah. Jenis air ini meliputi: air limpasan permukaan, air sungai, rawa atau danau yang terdapat di daerah tersebut, air buangan (limbah), dan mata air. Namun, air di bawah tanah merupakan air 
yang terdapat di bawah permukaan tanah (Gautama, 1999).

\subsection{Tujuan Penyaliran Tambang}

Meminimalkan air yang masuk ke dalam front penambangan serta mengeluarkan air dari area front penambangan (proses pemompaan). Untuk dapat melakukan pengendalian air tambang dengan baik perlu diketahui sumber dan perilaku air. Aspekaspek yang mendasari perencanaan penyaliran tambang adalah aspek hidrologi dan hidrogeologi, meliputi pengetahuan daur hidrologi, curah hujan, infiltrasi, air limpasan dan air tanah serta teknik penyaliran tambang (Suwandhi, 2004).

\subsection{Metode Penyaliran Tambang}

Penanganan masalah air dalam suatu tambang terbuka dapat dibedakan menjadi dua, yaitu:

\section{Mine drainage}

Merupakan upaya untuk mencegah masuknya air ke daerah penambangan. Hal ini umumnya dilakukan untuk penanganan air tanah dan air yang berasal dari sumber air permukaan. Cara yang biasa digunakan untuk mencegah agar air permukaan adalah dengan membuat saluran/paritan di sekeliling tambang atau lantai jenjang.

\section{Mine dewatering,}

Merupakan upaya untuk mengeluarkan air yang telah masuk ke daerah penambangan. Upaya ini terutama untuk menangani air yang berasal dari air hujan.

Beberapa metode penyaliran tambang adalah sebagai berikut :

\subsection{Membuat Sump di Dalam Front Tambang (Pit)}

Sistem ini diterapkan untuk membuang air tambang dari lokasi kerja. Air tambang dikumpulkan pada sumuran (sump), kemudian dipompa keluar. Pemasangan jumlah pompa tergantung pada kedalaman penggalian, dengan kapasitas pompa menyesuaikan debit air yang masuk ke dalam lokasi penambangan.

\subsection{Membuat Paritan}

Pembuatan parit sangat ideal diterapkan pada tambang terbuka open cast atau kuari. Parit dibuat berawal dari sumber mata air atau air limpasan menuju kolam penampungan, langsung ke sungai atau diarahkan ke selokan (riool). Dimensi parit diukur berdasarkan volume maksimum pada saat musim penghujan deras dengan memperhitungkan kemiringan lereng. Bentuk standar melintang dari parit umumnya trapezium (Hartono, 2008).

\subsection{Faktor - faktor yang Mempengaruhi Sistem Penyaliran Tambang}

Faktor - faktor yang harus dipertimbangkan dalam merancang sistem penyaliran pada tambang terbuka (Hartono, 2008) adalah :

1. Permeabilitas,

2. Rencana kemajuan rambang, dan

3. Curah hujan.

Data curah hujan yang akan dianalisa adalah besarnya curah hujan harian maksimum. Pengolahan data curah hujan meliputi:

1. Periode ulang hujan, dan

2. Hujan rencana.

Salah satu metode dalam analisa frekuensi yang sering digunakan dalam menganalisa data curah hujan adalah metode distribusi ekstrim, atau juga dikenal dengan metode distribusi Gumbel (Suwandhi 2004).

Persamaan Gumbel tersebut adalah sebagai berikut:

$$
X t=X+\partial / \partial n(Y t-Y n)
$$

$\mathrm{X}_{\mathrm{T}} \quad=$ perkiraan nilai curah hujan rencana $(\mathrm{mm})$

$\mathrm{X}=$ curah hujan rata-rata $(\mathrm{mm})$

$\partial \quad=$ simpangan baku (standar deviation)

$\partial \mathrm{n}=$ standar deviasi dari reduksi variate (standar deviation of thereduced variate), nilainya tergantung dari jumlah data

Yt $=$ nilai reduksi variate dari variable yang diharapkan terjadi pada periode ulang tertentu

Yn $\quad=$ koreksi rata-rata $($ reduced mean $)$ 

rumus :

Simpangan baku dihitung dengan

$$
\partial=\sqrt{\frac{\sum(X-\bar{X})^{2}}{n-1}}
$$

Dimana :

$$
\begin{array}{ll}
\partial & =\text { standar deviasi } \\
\mathrm{X} & =\text { nilai variat } \\
\overline{\mathrm{X}} & =\text { nilai rata-rata hitung variat } \\
\mathrm{n} & =\text { jumlah data }
\end{array}
$$

Nilai reduksi variat dihitung dengan menggunakan rumus :

$Y t=-\ln \left\{-\ln \left[\frac{T-1}{T}\right]\right\}$.

Dimana:

$\mathrm{Y} \quad=$ nilai reduksi variat dari variable yang diharapkan terjadi pada periode ulang tertentu

$\mathrm{T}=$ periode ulang (tahun)

Koreksi rata-rata (reduced mean) dihitung dengan menggunakan rumus :

Dimana:

$$
Y n=-\ln \left[-\ln \left\{\frac{(n+1-m)}{n+1}\right\}\right]
$$

$$
\begin{array}{ll}
\mathrm{Yn} & =\text { koreksi rata-rata (reduced mean) } \\
\mathrm{n} & =\text { jumlah data } \\
\mathrm{m} & =\text { urutan data }(1,2,3, \ldots)
\end{array}
$$

Nilai koreksi simpangan (reduced standard deviation ) ditentukan dengan rumus:

Dimana:

$$
\partial n=\sqrt{\frac{\sum(Y n-\overline{Y n})^{2}}{n-1}}
$$

$$
\begin{aligned}
\partial \mathrm{n}= & \text { standar deviasi dari reduksi variate } \\
& (\text { standar deviation of thereduced } \\
& \text { variate }), \text { nilainya tergantung dari } \\
& \text { jumlah data } \\
= & \text { koreksi rata-rata (reduced mean) } \\
= & \text { nilai rata-rata Yn } \\
\overline{Y n}= & \text { jumlah data }
\end{aligned}
$$

3. Intensitas curah hujan

Intensitas curah hujan adalah jumlah hujan per satuan waktu yang relatif singkat, dinyatakan dalam $\mathrm{mm} / \mathrm{jam}$, $\mathrm{mm} / \mathrm{menit}$, $\mathrm{mm} /$ detik. Perhitungan intensitas curah hujan satu jam dilakukan dengan menggunakan rumus Mononobe sebagai berikut (Suwandhi, 2004):

Dimana:

$$
I=\frac{R_{24}}{24}\left(\frac{24}{T c}\right)^{\frac{2}{3}}
$$




\subsection{Pemompaan}

Pompa berfungsi untuk memindahkan atau mengeluarkan air dari tempat yang rendah, yaitu air yang ada pada kolam penampungan (sump) pada lantai kerja penambangan ke tempat yang lebih tinggi (keluar tambang). Sesuai dengan prinsip kerjanya, pompa dibedakan atas :

1.Reciprocating pump,

2.Centrifugal pump, dan

3.Axial pump.

Dalam pemompaan dikenal istilah julang (head), yaitu energi yang diperlukan untuk mengalirkan sejumlah air pada kondisi tertentu. Semakin besar debit air yang dipompa, maka head juga akan semakin besar. Head total pompa untuk mengalirkan sejumlah air seperti yang direncanakan dapat ditentukan dari kondisi instalasi yang akan dilayani oleh pompa tersebut, sehingga julang total pompa dapat dituliskan sebagai berikut:

Dimana:

$$
\mathrm{H}=h_{s}+h_{v}+h_{f 1}+h_{f 2}
$$

$\mathrm{H}=$ head total pompa $(\mathrm{m})$

$\mathrm{h}_{\mathrm{s}} \quad=$ headstatis pompa $(\mathrm{m})$

$\mathrm{h}_{\mathrm{v}} \quad=$ head kecepatan $(\mathrm{m})$

$\mathrm{h}_{\mathrm{f} 1} \quad=$ head gesekan $(\mathrm{m})$

$\mathrm{h}_{\mathrm{f} 2} \quad=$ head belokan

Perhitungan berbagai julang pada pemompaan :

\section{Head statis $\left(\mathrm{h}_{\mathrm{s}}\right)$}

Dimana:

$$
h s=h_{2}-h_{1}
$$

$\mathrm{h}_{1} \quad=$ elevasi sisi isap $(\mathrm{m})$

$\mathrm{h}_{2} \quad=$ elevasi sisi keluar $(\mathrm{m})$

2. Head kecepatan

$$
h_{V}=\frac{V^{2}}{2 g}
$$

Dimana:

$$
\begin{aligned}
\mathrm{Hv}= & \text { head } \text { kecepatan }(\mathrm{m}) \\
\mathrm{v}= & \text { kecepatan aliran air dalam pipa } \\
& (\mathrm{m} / \text { detik }) \\
= & \text { percepatan gravitasi }\left(\mathrm{m} / \text { detik }^{2}\right)
\end{aligned}
$$

3. Head gesekan $\left(\mathrm{h}_{f 1}\right)$

$$
H f 1=f\left(\frac{L v^{2}}{2 D g}\right)
$$

Dimana:

$\mathrm{Q}=$ debit air limpasan $\left(\mathrm{m}^{3} /\right.$ detik $)$
$\mathrm{V}=$ kecepatan aliran dalam pipa (m/detik)

$\mathrm{L} \quad=$ panjang pipa $(\mathrm{m})$

$\mathrm{D} \quad=$ diameter pipa $(\mathrm{m})$

$\mathrm{f} \quad=$ koefisien kekasaran pipa

g $\quad=$ percepatan gravitasi bumi $\left(\mathrm{m} / \operatorname{detik}^{2}\right)$

4. Head belokan $\left(\mathrm{h}_{f 2}\right)$

$$
h_{f 2}=k\left(\frac{v^{2}}{2 g}\right)
$$

Dimana:

$\mathrm{k}=$ koefisien kerugian pada belokan

$$
\mathrm{k}=\left[0,131+1,847\left(\frac{\mathrm{D}}{2 \mathrm{R}}\right)^{3,5}\right] \times\left(\frac{\theta}{90}\right)^{0,5}
$$

$\mathrm{V} \quad=$ kecepatan aliran dalam pipa (m/detik)

$\mathrm{g} \quad=$ percepatan gravitasi bumi $\left(\mathrm{m} / \mathrm{detik}^{2}\right)$

$\mathrm{R}=$ jari-jari lengkung belokan $(\mathrm{m})$

$$
R=\frac{D}{\tan \frac{1}{2} \theta}
$$

$\Theta \quad=$ sudut belokan pipa (derajat)

$\mathrm{D} \quad=$ diameter pipa $(\mathrm{m})$

\subsection{Saluran Penyaliran}

Perhitungan kapasitas pengaliran suatu saluran air dilakukan dengan rumus manning ( Amin, 2000) sebagai berikut :

$$
Q=1 / n \times R^{2 / 3} \times S^{1 / 2} \times A
$$

Dimana:

$\mathrm{Q} \quad=\operatorname{debit}\left(\mathrm{m}^{3} /\right.$ detik $)$

$\mathrm{R} \quad=$ jari-jari hidrolik $(\mathrm{m})$

$\mathrm{S} \quad=$ kemiringan saluran $(\%)$

A $\quad=$ luas penampang basah $\left(\mathrm{m}^{2}\right)$

$\mathrm{n} \quad=$ koefisien kekasaran manning

\section{METODOLOGI PENELITIAN}

\subsection{Jenis Penelitian}

Jenis penelitian yang akan dilakukan peneliti ialah jenis penelitian yang tergolong kedalam jenis penelitian deskriptif dengan data berbentuk kuantitatif.

\subsection{Waktu dan Tempat Penelitian}

Penelitian dilakukan pada tanggal 24 Februari 2020 s.d. 24 April 2020 di PT Duta Alam Sumatera, berlokasi di di Desa Tanjung Baru, Kecamatan Merapi Barat, Kabupaten Lahat, Propinsi Sumatera Selatan.

\subsection{Metode Penelitian}


Masalah-masalah yang dibahas pada penelitian ini, dapat menggunakan beberapa metode penyelesaiannya sebagai berikut :

1. Studi literatur

Studi literatur adalah mengumpulkan dan mempelajari data-data yang didapat dari beberapa literatur seperti buku, jurnal, internet dan tulisan yang berkaitan dengan penelitian.

2. Observasi

Observasi lapangan adalah pengamatan langsung ke lokasi penelitian. Dalam penelitian ini dilakukan pengamatan langsung aktifitas dewatering.

3. Pengambilan data

Pengambilan data tergantung dari jenis data yang dibutuhkan, yaitu

a. Data primer

Data primer adalah data yang diperoleh dari pengamatan langsung dilapangan serta melalui bimbingan para pembimbing lapangan pada saat melakukan penelitian di lapangan meliputi debit masing-masing pompa dan dokumentasi alat dan lokasi penelitian.

b. Data sekunder

Data sekunder adalah data yang diperoleh dari data-data yang menunjang dalam penelitian meliputi data curah hujan, peta catchment area, luas catchment area, debit airtanah, debit evapotranspirasi, jam kerja pompa dan spesifikasi pompa dan pipa

4. Pengolahan data

Setelah data terkumpul kemudian dilakukan pengolahan data. Pengolahan data dilakukan secara manual terhadap data yang diperoleh dari pengamatan dilapangan maupun data perusahaan dengan panduan dari dasar teori yang sudah diperoleh dari bahan pustaka yang menunjang.

5. Pengambilan kesimpulan

Dari semua hasil pengolahan data maka akan didapatkan data mengenai aktifitas dewatering sehingga dapat diketahui masalah kemampuan sump yang ada untuk dijadikan suatu kesimpulan. Setelah itu, memberikan suatu saran yang dapat menunjang kinerja sistem penyaliran untuk perusahaan.

\section{HASIL DAN PEMBAHASAN}

\subsection{Hasil}

Sebagai bahan kajian data, penulis melakukan aktifitas pencarian data melalui diskusi dengan pembimbing serta observasi telah dilakukan selama penelitian berlangsung serta menghasilkan beberapa data yang dapat dijadikan sebagai pengolahan data meliputi perhitungan debit outlet pompa, perhitungan total volume air yang masuk dan keluar serta perhitungan kemampuan sump PT Duta Alam Sumatera.

\subsubsection{Perhitungan Debit Outlet Pompa}

Berdasarkan hasil perencanaan dari Mine Water Project dan Planning (MWPP) jumlah pompa yang dirental PT Duta Alam Sumatera sebanyak 3 pompa dan 2 pompa dari kontraktor PT ABL. Dengan rincian dua pompa kontraktor pihak ABL sedangkan dua pompa rental dari void Pit dua menuju ke void Pit 1 dan satu pompa rental dari void Pit 1 masuk menuju ke KPL 3. Pada pipa akan dipasang kondom yang fungsinya untuk menangkap lumpur yang pertama. Debit pompa aktual didapat dari pengukuran di lapangan sebesar 328 1/s dimana tekanan yang dihasilkan pompa sebesar 21 bar.

Tabel 4.1 Debit Outlet Pompa

\begin{tabular}{|c|c|c|c|}
\hline No. & Jenis Pompa & $\begin{array}{c}\text { Kap. Penampungan } \\
\text { (1) }\end{array}$ & liter/sekon \\
\hline 1 & MTP 02 & \multirow{6}{*}{69} & 87,34 \\
\hline 2 & МТP 03 & & 44,80 \\
\hline 3 & MTP 04 & & 81,17 \\
\hline 4 & MTP 05 & & 46,62 \\
\hline 5 & WP 08 & & 69 \\
\hline 6 & MTP 01 & & $\begin{array}{c}\text { Hose } \\
\text { Kompresor } \\
\text { Problem } \\
\end{array}$ \\
\hline \multicolumn{3}{|c|}{ Total } & 328 \\
\hline
\end{tabular}

Sumber: PT Duta Alam Sumatera, 2020

\subsubsection{Perhitungan Total Volume Air yang Masuk dan Keluar Sump PT Duta Alam Sumatera \\ Untuk mengetahui kemampuan sump} hal pertama yang dilakukan yaitu menghitung volume air yang masuk dari hujan, air tanah dan air evapotranspirasi dan mengetahui air yang keluar karena aktifitas pemompaan di sump PT Duta Alam Sumatera. 


\subsubsection{Perhitungan Curah Hujan Rencana dan Intensitas Curah Hujan}

Perhitungan curah hujan rata- rata menggunakan metode Gumbell dengan data curah hujan 5 tahun terakhir yang dimulai dari 2015 sampai 2019 dengan jumlah data 30 data dapat dilihat pada lampiran 2. Dengan curah hujan rata- rata $(\mathrm{Xi}) 55,7 \mathrm{~mm} / \mathrm{hari}$, reduce mean (Yn) sebesar 3,417637092, Simpangan Baku (standart deviation) atau $\mathrm{S}$ sebesar 9,3 $\mathrm{mm} /$ hari, koreksi simpangan baku (reduced standar deviation) $1,13 \mathrm{~mm} / \mathrm{hari}$, reduce variate $(\mathrm{Yt})$ 1,4999. Setelah semua data di dapat maka baru dapat mencari besar curah hujan rencana, nilai curah hujan rencana selama 5 tahun sebesar (Xt) $65,23 \mathrm{~mm} /$ hari.

Untuk mencari intensitas curah hujan digunakan persamaan mononobe dengan nilai curah hujan maksimum $\left(\mathrm{R}_{24}\right)$ sebesar 65,23 $\mathrm{mm}$ dan rata-rata jam hujan $(\mathrm{t})$ sebesar 1,22 jam setelah semua data didapat maka intensitas curah hujan sebesar 19,99 mm/jam.

\subsubsection{Perhitungan Debit Limpasan, Debit Evapotranspirasi, Debit Air yang Masuk dan Debit Air Keluar Tambang \\ Untuk menghitung debit air limpasan} terlebih dahulu harus mengetahui luas daerah tangkapan hujan (catchment area). Dengan menggunakan software minescape ventyx 5.7 yang diolah langsung oleh mine plan departement of engineering PT Duta Alam Sumatera dapat ditentukan luas daerah tangkapan hujan (catchment area) Kolam Pengendap Lumpur (KPL 3) sebesar 28,72 Ha atau $287.200 \mathrm{~m}^{2}$. Daerah tangkapan hujan pada Pit penambangan PT Duta Alam Sumatera dibatasi oleh tanggul-tanggul pada sisi selatan barat dan timur dari Pit tersebut. Keadaan tangkapan hujan berupa tanah gundul dengan kemiringan $>15^{\circ}$ sehingga nilai koefisien limpasannya (C) untuk kajian teknis ini adalah 0,9 dengan pertimbangan bahwa kondisi pada lokasi penelitian adalah dasar Pit dan jenjang (Pit floor dan bench). Selain itu, tata guna lahan tutupannya adalah tanpa tumbuhan dan lokasi tambang. Setelah mengetahui luas catchment area (A) untuk menentukan debit air limpasan dengan intensitas curah hujan (I) $19,99 \mathrm{~mm} / \mathrm{jam}$ dan koefisien limpasan (C) 0,9. Perhitungan debit air limpasan dengan metode rasional sehingga diperoleh besar debit limpasan sebesar 5.115,6 $\mathrm{m}^{3} / \mathrm{jam}$.

Air yang masuk ke tambang akan mengalami proses penguapan atau evapotranspirasi karena lokasi penambangan sudah tidak memiliki tanaman dan lahan vegetasi. Besarnya evapotranspirasi yang terjadi dapat dihitung dengan rumus TurcLangbein-Wund. Dimana untuk Nilai $P$ didapat dari data curah hujan 5 tahun terakhir dan $\mathrm{L}(\mathrm{T})$ didapat dari data sekunder, maka didapat intensitas evapotranspirasi (ET) sebesar 2 x $10^{-4} \mathrm{~m}^{3} / \mathrm{jam}$ dan luas evapotranspirasi sebesar $2.900,72 \mathrm{~m}^{2}$ maka nilai debit evapotranspirasi sebesar 0,52 $\mathrm{m}^{3} / \mathrm{jam}$.

Dengan debit limpasan sebesar 5.115,6 $\mathrm{m}^{3} / \mathrm{jam}$ debit airtanah sebesar $0 \mathrm{~m}^{3} /$ hari dan $0,52 \mathrm{~m}^{3} / \mathrm{jam}$ untuk debit evapotranspirasi, maka didapatkan total air yang masuk $511.789,82 \mathrm{~m}^{3} /$ hari. Setelah mendapatkan volume air masuk maka harus juga mengetahui volume air keluar yang di alirkan menggunakan pompa ke Kolam Pengendap Lumpur (KPL) 3. Dengan jam kerja pompa sebesar $20 \mathrm{jam} / \mathrm{hari}$ dan total debit pompa bulan Maret $1.182 \mathrm{~m}^{3} / \mathrm{jam}$ sehingga volume air keluar sebesar $709.200 \mathrm{~m}^{3} / \mathrm{jam}$ untuk periode bulan Maret.

\subsubsection{Perhitungan Kemampuan Sump}

Dengan sistem pemompaan yang saat ini diterapkan di PT Duta Alam Sumatera sump Pit 2, yaitu sistem paralel dengan letak pompa saat ini berada di elevasi $62 \mathrm{mdpl}$ untuk pipa inlet dan elevasi 110 mdpl untuk pipa outlet dengan perbedaan elevasi $48 \mathrm{mdpl}$ dan kapasitas pompa berdasarkan data pengukuran menggunakan kecepatan (opeating speed) $1600 \mathrm{rpm}$. menggunakan pipa HDPE (hight density polyetylene) dengan panjang pipa $6 \mathrm{~m}$. Pompa yang digunakan untuk mengeluarkan air dari sump PT Duta Alam Sumatera adalah pompa armor PM-6 dengan jumlah pompa sebanyak 6 unit pompa (5 unit pompa di sump Pit 2 dan 1 pompa di 
sump Pit 1). Jumlah pipa sebanyak 20 pipa. Untuk kapasitas 1 Pompa sebesar $250 \mathrm{~m}^{3} / \mathrm{jam}$. Pemompaan dilakukan dari sump langsung ke arah atas melalui pipa yang di pasang melewati jenjang tambang sampai pada outlet pompa kemudian menuju KPL 3.

Tabel 4.2 Dimensi Sump

\begin{tabular}{|c|l|c|}
\hline No. & \multicolumn{1}{|c|}{ Komponen Sump } & Ukuran (m) \\
\hline 1 & Panjang Permukaan Sump & 316 \\
\hline 2 & Lebar Permukaan Sump & 316 \\
\hline 3 & Panjang Dasar Sump & 285 \\
\hline 4 & Lebar Dasar Sump & 285 \\
\hline 5 & Kedalaman Sump & 30 \\
\hline
\end{tabular}

Sumber : PT Duta Alam Sumatera, 2020

Dimensi sump ditentukan dengan membandingkan akumulasi jumlah air yang masuk pada perhitungan jumlah dan rata-rata jam serta hari hujan sehingga dapat diketahui ukuran maksimal sump yang dibutuhkan. Jumlah sump ada 2 dimana sump Pit 1 berada di sebelah timur sump Pit 2 dan sump Pit 2 berada di samping kanan PT Wirasana Energi Bara (WEB). Data lapangan yang diperoleh diamater pipa luar adalah $0,25 \mathrm{~m}$ atau 10 inchi sedangkan untuk diameter dalam adalah 0,20 $\mathrm{m}$ atau 8 inchi dengan ketebalan pipa adalah 2 cm. Luas Sump 16,11 Ha. Panjang satu buah pipa HDPE adalah $6 \mathrm{~m}$, maka panjang jalur perpipaan sebesar $120 \mathrm{~m}$.

Tabel 4.3 Deskripsi Sump

\begin{tabular}{|c|l|c|}
\hline No. & \multicolumn{1}{|c|}{ Deskripsi } & Keterangan \\
\hline 1 & Kapasitas sump & $3.500 .000 \mathrm{~m}^{3}$ \\
\hline 2 & Volume awal sump & $2.700 .000 \mathrm{~m}^{3}$ \\
\hline 3 & Volume air masuk & $5.115,08 \mathrm{~m}^{3} / \mathrm{jam}$ \\
\hline 4 & Volume air keluar & $709.200 \mathrm{~m}^{3} / \mathrm{jam}$ \\
\hline 5 & $\begin{array}{l}\text { Volume akhir sump periode } \\
\text { bulan Maret }\end{array}$ & $\begin{array}{c}1.995 .915,08 \\
\mathrm{~m}^{3} / \mathrm{jam}\end{array}$ \\
\hline 6 & Persentase kemampuan sump & 57 \\
\hline
\end{tabular}

Desain bentuk dan geometri sump dihitung berdasarkan jumlah air yang masuk serta air yang keluar dari sump. Terlihat dari tabel 4.3 bahwa kapasitas sump sebesar $3.500 .000 \mathrm{~m}^{3}$ dan volume awal sump $2.700 .000 \mathrm{~m}^{3}$ didapat dari departement of engineering 2020 sedangkan untuk volume air masuk sebesar 5.115,08 $\mathrm{m}^{3} / \mathrm{jam}$ dan volume air keluar $709.200 \mathrm{~m}^{3} / \mathrm{jam}$ didapat dari perhitungan pengolahan data. Volume akhir sump sebesar 1.995.915,08 $\mathrm{m}^{3} / \mathrm{jam}$ didapat dari penjumlahan volume awal dan volume air yang masuk lalu dikurangi volume air yang keluar sedangkan persentase kemampuan sump sebesar $57 \%$ didapat dari pembagian antara volume akhir bulan Maret dan kapasitas sump sehingga menunjukkan bahwa persentase kurang dari $100 \%$.

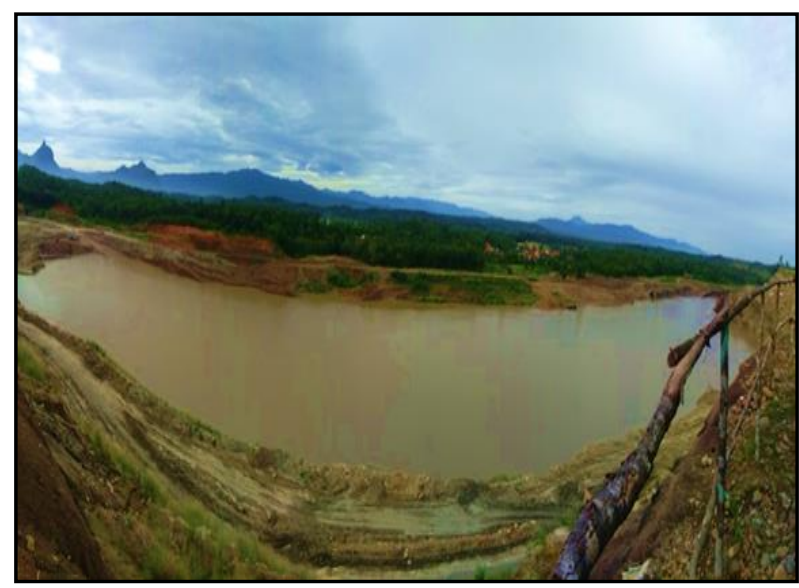

Gambar 4.1 Sump Pit 2

\subsection{Pembahasan}

Dari hasil pengolahan data maka selanjutnya dilakukan analisis debit outlet masing-masing pompa PT Duta Alam Sumatera, Analisis total debit air yang masuk ke sump dan total debit air yang keluar Pit 2 PT Duta Alam Sumatera serta kemampuan sump untuk menampung airyang masuk pada sump Pit 2 PT Duta Alam Sumatera.

\subsubsection{Debit Outlet Pompa}

Outlet Pompa merupakan tempat penampungan air yang berasal dari pemompaan sump void 1 dan Pit 2. Berdasarkan hasil penelitian yang penulis paparkan diatas menunjukkan bahwa sistem penyaliran tambang di PT Duta Alam Sumatera menggunakan metode mine dewatering, yaitu air yang ada pada kolam penampungan dipompa ke kolam pengendapan. Terlihat dari tabel 4.1 debit outlet yang didapat, yaitu 328 liter/sekon. Pengukuran dilakukan pada tanggal 27 Februari 2020. 
Pengukuran dilakukan dengan menampung air yang mengalir menggunakan ember yang diketahui volumenya yaitu 69 liter lalu menghitung lamanya ember tersebut penuh oleh air yang mengalir menggunakan stopwatch lalu catat hasil dari stopwatch. Dimana saat pengukuran ada satu pompa yang breakdown sehingga tidak bisa dihitung debit outlet pompa. Penggunaan 5 unit pompa yang dipasang paralel dengan jam operasional pompa yang kurang dan sering dimatikan sehingga menghasilkan pompa tidak maksimal dalam berkerja dan mendapatkan nilai debit yang kecil.

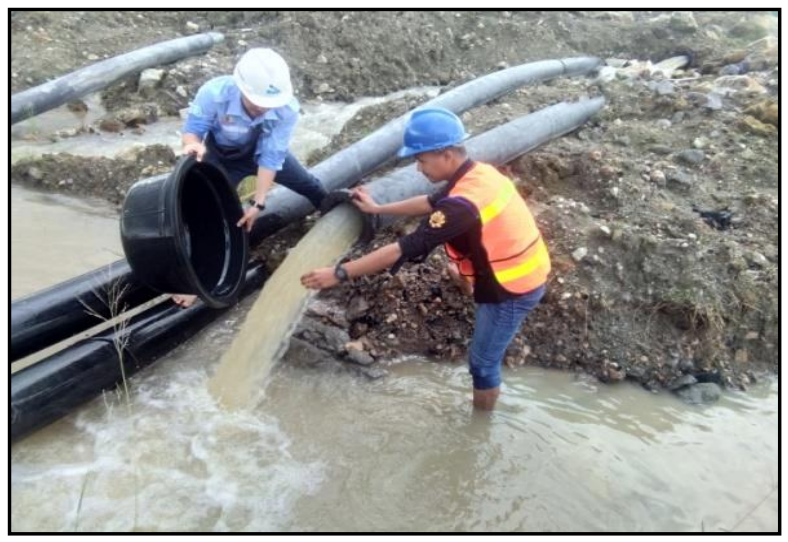

Gambar 4.2 Pengukuran Debit Outlet Pompa

Pengukuran debit outlet pompa dilakukan sebanyak empat kali percobaan akan tetapi dikarenakan percobaan yang keempat banyak yang gagal dalam menghitung waktu aliran maka hanya diambil tiga kali percobaan. Data yang diambil untuk pengolahan data yaitu data rata-rata dari tiga kali percobaan. Pengukuran debit outlet pompa dilakukan sebanyak tiga kali dikarenakan untuk mendapatkan hasil yang lebih akurat.

\subsubsection{Total Volume Air yang Masuk dan Keluar Sump PT Duta Alam Sumatera}

Data curah hujan digunakan sebagai dasar perhitungan untuk melakukan perkiraan curah hujan rencana. Data curah hujan yang didapat harus memuat berbagai data yaitu data curah hujan bulanan, curah hujan maksimum, jam hujan, dan hari hujan. Data tersebut diolah dengan menggunakan metode analisa Gumbel.
Penentuan curah hujan harian rencana menggunakan curah hujan harian maksimum dimaksudkan untuk mengatasi permasalahan yang mungkin terjadi pada saat curah hujan mencapai angka maksimum sehingga desain paritan maupun sump dapat menampung debit aliran air limpasan hujan dalam kondisi dan jumlah yang maksimum.

Hasil tinjauan lapangan menunjukkan pada lereng-lereng jenjang di lokasi penelitian tidak memperlihatkan adanya rembesan air tanah pada lereng tambang meskipun pada musim hujan karena diketahui daerah kering maka untuk debit airtanah menggunakan asumsi nol. Kondisi ini disebabkan karena kegiatan penambangan berada di atas bukit dengan jenis tanah dan batuan berjenis clay atau lempung yang memiliki permeabilitas yang kecil. Dengan melihat hal tesebut dapat diasumsikan bahwa airtanah yang ada didaerah penambangan tidak terlalu berpengaruh terhadap aktifitas penambangan.

Limpasan adalah semua air yang mengalir akibat hujan yang bergerak dari tempat yang lebih tinggi ke tempat yang lebih rendah tanpa memperhatikan asal atau jalan yang di tempuh sebelum mencapai saluran. Perhitungan debit air yang masuk ke area KPL 3 merupakan akumulasi dari air limpasan hujan dan air pemompaan dari sump Pit 2. Air yang terakumulasi ini akan berkurang secara evaporasi dikarenakan suhu sehingga debit masuk total akan dikurangi dengan debit evaporasi yang terjadi pada suhu tertentu. Total debit air yang masuk ke sump, yaitu sebesar $511.789,82 \mathrm{~m}^{3} / \mathrm{jam}$ sedangkan Total debit air yang keluar dari sump sebesar $709.200 \mathrm{~m}^{3} / \mathrm{jam}$ menunjukkan bahwa banyak air yang keluar daripada air yang masuk dikarenakan aktifitas pemompaan yang dilakukan untuk mencegah terjadinya banjir di permukaan kerja tambang.

Catchment area didapat dengan cara menghubungkan titik-titik tertinggi pada peta batas pit penambangan dengan memperhatikan arah aliran air di daerah tersebut hingga didapatkan sebuah polygon tertutup. Dari garis polygon ini, dilakukan perhitungan dengan membuat opsi brief detail pada garis polygon 
dari masing-masing catchment area. Luas dari polygon tersebut dapat dihitung dengan menggunakan planimeter, millimeter block, atau dengan bantuan software. Catchment area inpit (di dalam area penambangan) berbeda dengan outpit (di luar penambangan) dikarenakan untuk menghitung debit keseluruhan yang masuk ke dalam bukaan tambang (pit) perlu menghubungkan titik tertinggi pada batas pit penambangan sedangkan untuk diluar area penambangan perlu menghitung kembali luas catchment area di Wilayah Izin Usaha Pertambangan (WIUP) PT Duta Alam Sumatera sehingga catchment area inpit dan outpit perlu dipisah dikarenakan berbeda.

Bentuk kolam pengendapan yang digunakan di PT Duta Alam Sumatera yaitu berbentuk persegi panjang dan berkelokkelok. Kolam pengendapan dibuat berkelok kelok supaya kecepatan air dan material yang masuk dapat diperkecil, dengan kecepatan aliran yang kecil maka waktu yang dibutuhkan oleh air dan material untuk keluar dari kolam pengendapan semakin lama, sehingga material mempunyai waktu yang cukup untuk mengendap. Kolam pengendapan yang digunakan PT Duta Alam Sumatera terdiri dari 5 kompartemen yang dibuat sekat masingmasing kompartemen.

\subsubsection{Kemampuan Sump}

Analisis sump dibutuhkan untuk menentukan durasi sump akan penuh terisi air hujan. Tujuannya untuk menghindari sump overload sehingga perlu dilakukan aktifitas pemompaan. Air yang telah terakumulasi pada sump dipompakan menuju parit yang berbentuk trapesium. Lalu menuju kolam pengendapan lumpur 3 sebelum dilepas menuju aliran Sungai Pule. Air dari kolam pengendapan akan mengalir ke kolam penjernihan melalui canal/parit. Dimana kolam penjernihan air merupakan kolam air yang telah jernih berasal dari kolam penampung lumpur dan telah diberlakukan treatment seperti pemberian kapur dan tawas sebelum dilepas menuju aliran anak sungai. Bentuk paritan yang dirancang dalam penelitian ini adalah trapesium. Dimana air yang sudah berada di kolam penjernih ini siap dilepaskan ke masyarakat luas melalui pitu air. Di kolam penjernih air ada beberapa kompartemen (kompartemen 1,2 dan 3) yang berfungsi untuk mengendapkan lumpur yang tidak terendapkan di kolam pengendap lumpur.

Kolam penampungan yang digunakan di PT Duta Alam Sumatera, yaitu main sump dengan kapasitas sump $3.500 .000 \mathrm{~m}^{3}$ dan volume akhir sump periode bulan Maret 1.995.915,08 $\mathrm{m}^{3} / \mathrm{jam}$ sehingga didapat persentase kemampuan sump yang kurang dari $100 \%$ menunjukan bahwa sump yang digunakan PT Duta Alam Sumatera mampu menampung air yang masuk di area pit IUP PT Duta Alam Sumatera sehingga tidak diperlukan lagi pendalaman sump atau pembuatan sump baru.

\section{KESIMPULAN DAN SARAN}

\subsection{Kesimpulan}

Kesimpulan dari penelitian ini sebagai berikut :

1. Debit outlet pompa sebesar $1.182 \mathrm{~m}^{3} / \mathrm{jam}$ dikarenakan penggunaan 5 unit pompa yang dipasang paralel dengan jam operasional pompa yang kurang sehingga pompa tidak maksimal dalam berkerja.

2. Total debit air yang masuk ke sump sebesar $5.115,08 \mathrm{~m}^{3} / \mathrm{jam}$ dan total debit air yang keluar dari sump sebesar $709.200 \mathrm{~m}^{3} / \mathrm{jam}$. Hal ini menunjukkan bahwa banyak air yang keluar daripada air yang masuk dikarenakan aktifitas pemompaan yang dilakukan untuk mencegah terjadinya banjir di permukaan kerja tambang.

3. Persentase kemampuan sump sebesar $57 \%$ sehingga dapat disimpulkan persentase kurang dari $100 \%$. Sump yang digunakan di PT Duta Alam Sumatera sudah mampu menampung air yang masuk di area Pit PT Duta Alam Sumatera sehingga tidak diperlukan lagi penambahan sump atau pendalaman sump.

\subsection{Saran}


Saran yang dapat disampaikan penulis terhadap hasil penelitian yang dilakukan, yaitu:

1. Perlunya perawatan pompa yang dilakukan secara berkala dan terjadwal untuk menghindari kerusakan pompa pada saat jam operasi.

2. Sebaiknya dilakukan pengecekan debit aktual pada outlet pompa secara rutin, agar performa harian pompa dapat diketahui.

3. Pada saat proses penggalian, sebaiknya memperhatikan kemiringan lantai bukaan tambang sehingga air dapat mengalir dengan baik menuju sump.

\section{DAFTAR PUSTAKA}

Arnando, Tomi. 2019. Evaluasi Kapasitas Pompa pada sistem penirisan tambang batubara. Politeknik Akamigas Palembang : "Tugas Akhir Tidak Diterbitkan".

Andrianto, D dan Kasim, T. 2019. Perencanaan Sistem Penyaliran Tambang Batubara PT. Rajawali Internusa Jobsite PT. Indah Jaya Abadi Pratama Lahat, Sumatera Selatan. Jurnal Bina Tambang. 4(3). Hal. 90

Aziz, Syaifullah dan Kasim, Tamrin. Evaluasi Sistem Penyaliran Tambang Batubara Pada Pit Block $B$ Di Pt Minemex Indonesia Kabupaten Sarolangun, Jambi. Jurnal Bina Tambang. 4 (1).

C.D. Soemarto. 1987. Hidrologi Teknik. Surabaya. Usaha Nasional.

Fikri, I. 2013. Sistem Penyaliran Tambang.URL:ivanmiftahulfikri92.blogspot.co m/2013/10/sistem-penyaliran-tambang.html. diakses tanggal 20 maret 2020.

Gautama, RS.. 1999. Sistem Penyaliran Tambang. Institut Teknologi Bandung.

Kite, G. W., 1977, Frequency and risk analyses in hydrology, Water Resources Publications, Fort Collins, Colorado.

Kurniawan, E. 2009. Analisis Debit dan Muka Air Banjir Sungai Simpang Aurlemau dengan
Adanya PLTA Musi Kabupaten Bengkulu Utara. Universitas Indonesia. Skripsi. DKI Jakarta.

Noname. 2020. Debit Air. https://ilmugeografi.com/ilmubumi/hidrologi/debit-air. Diakses tanggal 20 Maret 2020.

Noname. 206. Pompa Armor. https://ptpms.com/dewatering-pump. Diakses tanggal 2 Agustus 2020.

Putra, A. dan Ariyanto. Kajian Teknis Optimalisasi Pompa Pada Sistem Penyaliran Tambang Bawah Tanah Di PT Cibaliung Sumber Daya, Provinsi Banten: 217.

Sepniko, R., et. al.. Kajian Teknis Sistem Penyaliran Tambang Terbuka Pada Penambangan Batubara Blok B PT Minemex Indonesia Desa Talang Serdang Kecamatan Mandiangin Kabupaten Sarolangun Provinsi Jambi. Jurnal Bina Tambang. 3(4), Hal. 1456.

Seyhan, E. 1990. Dasar-dasar Hidrologi. Terjemahan Sentot Subagyo. Yogyakarta: Gajah Mada University Press.

Sibarani, U.S., et. al.. 2016. Analisa Teknis Mine Dewatering Terhadap Rencana Tiga Tahun Penambangan Hingga Tahun 2016 Di Pit Blok Barat PT Muara Alam Sejahtera Kabupaten Lahat.

Soewarno. 1995. Hidrologi Jilid I. Bandung: Nova.

Sularso, dan Tahara, H. 1991. Pompa dan Kompresor. PT Pradnya Paramitha, Jl. Kebon Sirih 46, Jakarta, Hal. 13-39.

Suwandi, Awang. 2004. Dasar dasar Ilmu Air Tanah. Jakarta. Erlangga 
P-ISSN: 2089-5925 E-ISSN: 2621-9328

Antrant

Jurnal Teknik Patra Akademika

PATA

Arademika

Volume 11 No. 01 Juli 2020 